\title{
An artificial X-ray wire test emitter and calculations on the resolution and field of view of $\mathrm{X}$-ray pinhole optics by simulation.
}

\author{
A.Vella ${ }^{a}$, A.A.M.Munoz ${ }^{a}$, M.J.F.Healy ${ }^{a}$, D.W.Lane ${ }^{a}$, D.Lockley ${ }^{b}$ \\ ${ }^{a}$ Cranfield Forensic Institute, Cranfield University, Defence Academy of the United \\ Kingdom, Shrivenham, SN6 8LA; ${ }^{\mathrm{b}}$ Counter Terrorism \& Security Division, Dstl, Fort \\ Halstead, United Kingdom
}

\begin{abstract}
The PENELOPE Monte Carlo simulation code was used to evaluate pinhole mask parameters for X-ray backscatter imaging in a security application. This work makes four major contributions: it describes a convenient efficient test object for evaluating X-ray optics, it converts the PENELOPE output into a simulated CCD image, it compactly outlines how image characteristics can be simply and reproducibly quantified, and it gives guidance on suitable materials and geometries for pinhole masks for X-ray imaging that could be applied to more complicated X-ray optics, such as coded masks. A novel test object X-ray emitter with the shape of a thin wire was specifically designed to explore the effect of mask material thickness and pinhole aperture diameter on image quality. Setting the test object to be the X-ray emitter rather than being a passive scatterer increases computational speed. The photon energy distribution of the artificial test object was set flat between selected energy limits to avoid the model being specific to any particular X-ray source technology. The modelled detector is an array of 1040 x 1392 pixels' area detector inside a lead-lined camera housing. The pixelated detector was modelled by digitising the surface area represented by the PENELOPE phase space file and integrating the energies of the photons impacting each pixel with MATLAB code. The pinhole must be wide enough for sufficient field of view, whilst narrow enough for sufficient spatial resolution and the mask material needs to be thick enough to absorb most X-rays. When the mask material was too thick and the aperture too narrow, a collimation effect occurred. The consequence of excess collimation in a coded aperture is partial coding giving poor image reconstruction. Pure tungsten appears the most versatile material tested, where a $2 \mathrm{~mm}$ thickness and $2 \mathrm{~mm}$ aperture gives the most appropriate image characteristics for X-ray security imaging.
\end{abstract}

Keywords: PENELOPE Monte Carlo code, X-ray backscatter, X-ray imaging, pinhole masks, image processing

\section{Introduction}

X-ray imaging by backscatter rather than transmission opens new possibilities in the fields of medical imaging, industrial non-destructive testing and security screening, especially where physical access can be an issue. However, imaging by backscatter requires some form of Xray optics to attribute photons as being scattered or generated from some region of a target. Transmission radiography avoids optics just by the X-ray source being a small point; this achieves successful transmission images but would still fail to image fluorescence generated

Published by Elsevier. This is the Author Accepted Manuscript issued with: Creative Commons Attribution Non-Commercial Licence (CC:BY:NC 4.0). The final published version (version of record) is available online at DOI: 10.1016/j.nima.2018.07.049. Please refer to any applicable publisher terms of use. 
Nuclear Instruments and Methods in Physics Research Section A: Accelerators, Spectrometers, Detectors and Associated Equipment Volume 905, 11 October 2018, Pages 119-128

https://doi.org/10.1016/j.nima.2018.07.049

widely throughout the target. In this work, a simulation code was used to rapidly and costeffectively design and forecast the characteristics of options for X-ray backscatter optics. The Monte Carlo simulation tool PENELOPE [1] was chosen for its versatility and the transparency of its coding and underlying principles.

This work focuses on pinhole imaging systems, although the principles can be applied to coded apertures [2] [3] which have the potential to reduce image acquisition times. For a well-shielded camera, the only X-rays reaching the detector would be those passing through the aperture of the pinhole, and those penetrating the bulk of the mask or the reduced thickness obliquely through the pinhole edges. An ideal pinhole mask would have a very narrow aperture to give high spatial resolution and would be thick enough to prevent X-rays leaking through the surrounding material. However, thick masks can restrict the field of view and could give rise to partial coding in coded aperture systems [4]. Pinhole collimation has extensively been the object of investigation in X-ray and gamma-ray imaging [5] [6]. Pinholes are particularly suitable for high-resolution applications in medicine, defence, and industry. They combine ease of fabrication and a magnifying geometry, which is important to reduce any constraints imposed on spatial resolution by the detector pixel size [7].

The aim of this work is to propose ideal thicknesses and pinhole diameters for materials chosen for manufacturing pinhole and coded aperture masks for backscatter imaging [8] for a viable security screening application. However, the principle of this work can be applied to any pinhole based imaging systems.

\section{Materials and methods}

\subsection{The imaging system and modelling with PENELOPE}

The illustrative X-ray backscatter imaging system comprises a silicon detector enclosed by lead shielding, a brass rotation stage, and a pinhole mask placed in front of the rotation stage (see figure 1a). Sub-tools of PENELOPE (PENGEOM [9] and PENMAIN [10]) were used to design the imaging system and execute the Monte Carlo simulation. The mask is simulated for three different materials, three thicknesses and three aperture sizes. Each material was examined at three thicknesses without the pinhole to characterise the leakage through the Non-Commercial Licence (CC:BY:NC 4.0). The final published version (version of record) is available online at DOI: 10.1016/j.nima.2018.07.049. Please refer to any applicable publisher terms of use. 
Nuclear Instruments and Methods in Physics Research Section A: Accelerators, Spectrometers, Detectors and Associated Equipment Volume 905, 11 October 2018, Pages 119-128

https://doi.org/10.1016/j.nima.2018.07.049

mask material. The leakage spectra were generated in PENELOPE as energy-probability distributions. Then, the same simulated experiment was repeated by adding to each of three thicknesses and each of three materials a pinhole aperture of three different diameters. The simulated 'image' at the silicon detector was then collected as a phase-space file by the main program PENMAIN and was processed using MATLAB [11] to show the overall detected energy spectrum, and explore the noise, contrast and resolution. The X-ray source and test object are discussed in section 2.3.

\subsection{Designing the camera in PENGEOM}

The physical imaging system modelled comprises a Gemstar X-ray detector in a lead-lined black aluminium case. The case is fixed to an aluminium mount which is clamped securely to an optical bench. Attached to the front of the camera case is a $100 \mathrm{~mm}$ lead lined aluminium extension tube, which supports a brass rotation stage. The inner face of the rotation stage is lined with a $4 \mathrm{~mm}$ lead sheet. The pinhole mask is supported at the very front of the camera in an aluminium plate attached to the stage, and the whole system is tightly sealed, other than the apertures of the pinhole optic. The experimental camera is shown in figure 1a. The model of the camera replicates the relevant features of the experimental setup, and can be seen in figures 1b-c. It contains the following components:

- The 90 mm pinhole mask (pink) with a thickness of either $0.5,1,2,3,4,5,6,7,8,9$ and $10 \mathrm{~mm}$ and an aperture diameter of either 1,2 or $3 \mathrm{~mm}$.

- A $200 \mathrm{~mm}$ diameter aluminium support disk (red) $10 \mathrm{~mm}$ thick, with a $90 \mathrm{~mm}$ diameter inner hole.

- The $200 \mathrm{~mm}$ wide brass rotation stage (purple), $47 \mathrm{~mm}$ thick, with a $90 \mathrm{~mm}$ diameter inner hole;

- The silicon detector (orange) $92.4 \times 123.2 \mathrm{~mm}$, sitting $166 \mathrm{~mm}$ behind the pinhole.

- Two $166 \mathrm{~mm}$ diameter aluminium cylinders (green and red) to support the pinhole and detector.

- The volume surrounding the detector was filled with air to make the simulation more realistic. Air is represented in yellow/gold in the detector section on figure 1c.

Published by Elsevier. This is the Author Accepted Manuscript issued with: Creative Commons Attribution Non-Commercial Licence (CC:BY:NC 4.0). The final published version (version of record) is available online at DOI: 10.1016/j.nima.2018.07.049. Please refer to any applicable publisher terms of use. 
Nuclear Instruments and Methods in Physics Research Section A: Accelerators, Spectrometers, Detectors and Associated Equipment Volume 905, 11 October 2018, Pages 119-128

https://doi.org/10.1016/j.nima.2018.07.049

The model is based on a real detector and camera in use at Cranfield University. However, the general principles here shown are applicable for any pinhole based imaging system, such as coded masks.

\subsection{Thin wire $X$-ray emitter test object}

The aim of the work is to evaluate the spatial resolution and field of view of pinhole optics with a view to making broad general recommendations on suitable pinhole mask geometries and materials. The problems in doing this are that performing separate simulations to determine resolution and field of view would be computationally time consuming, and that the X-ray transmission of the mask material surrounding the pinhole depends on the energy distribution of the particular X-rays being imaged. To minimise these problems and establish consistency, a novel simple yet test object was conceived that allowed both spatial resolution and field of view to be calculated from a single simulation. It also tests pinholes under a simple fixed 'standard' energy spectrum that does not distort the final recommendations towards any particular type of X-ray generator, setting, or the different materials in the object being imaged, that all emit differently. To do this, the test object was set to be thin to reveal spatial resolution, simultaneously long to test field of view, and also to be its own flat spectrum X-ray emitter. This 'emitter' object also significantly increased computational speed over a passive object backscattering incident X-rays.

The test object is shown in figure $1 \mathrm{~b}$ as the long thin blue cylinder placed $166 \mathrm{~mm}$ in front of the 'purple' pinhole mask to give a magnification of unity. It was set to be narrow $(0.3 \mathrm{~mm})$ so that broadening reveals resolution deterioration caused by the imaging system. The extreme thinness of the object was expected to result in a Gaussian image profile used to calculate the resolution of the system in terms of its Full Width at Half Maximum (FWHM). It was set to be long $(46 \mathrm{~mm})$ where any reduction in its length in the image reveals the collimation effect of the pinhole reducing the Field of View (FOV).

Published by Elsevier. This is the Author Accepted Manuscript issued with: Creative Commons Attribution Non-Commercial Licence (CC:BY:NC 4.0). The final published version (version of record) is available online at DOI: 10.1016/j.nima.2018.07.049. Please refer to any applicable publisher terms of use. 
Nuclear Instruments and Methods in Physics Research Section A: Accelerators, Spectrometers, Detectors and Associated Equipment Volume 905, 11 October 2018, Pages 119-128

https://doi.org/10.1016/j.nima.2018.07.049

Backscatter imaging is usually performed with a source of X-rays near the camera directed at the target area. X-rays scatter from the target area in all directions, including back to the camera. However, to test the characteristics of various pinhole masks, it is computationally more efficient to make the test object the source of X-rays. The alternative would be to unnecessarily simulate X-rays that miss the 'wire like' object, or ones that hit the wire and undergo various radiation interactions and yet still emerge with path directions that would clearly miss the camera.

Emission was restricted to a $20^{\circ}$ cone in the forward direction to match the area of the mask and the photons generated had equal probability to be produced everywhere within the source wire. In our case, the test object generated photons with a uniform yield across the defined energy range so that the transmission function of the pinhole mask is easily apparent and to avoid the findings being specific to pyroelectric or thermionic sources with different anode targets or filters for hardening the beam. Simulation permits any mono-energetic, polychromatic, point or extended X-ray source to be modelled whether it is physically feasible yet or not. This allows the user to simulate current real sources or identify the nature of future sources that might be particularly suitable for imaging or materials characterisation. Because of the unique emission of the thin wire emitter, it was not possible to replicate it for a real laboratory experiment.

The power of physical experiment is that it has the capacity to establish beyond reasonable doubt how one particular physical system performs under the particular set of conditions tested. However, to forecast general trends under widely varying conditions then physical experiments may not only be too expensive, time consuming and constrained, but also be less reliable than simulations. This can arise through anything from vibrations to temperature changes causing misalignment, so for the purpose of this paper where it is currently not physically possible to provide a broad standard energy distribution anyway, simulation alone was considered sufficient. However, how this artificial test object could potentially give rise to artefacts (or neglect real phenomena) in real systems should be considered. Firstly, for a real test object illuminated by an external source inside a building there will be scattering reaching the camera housing from $4 \pi$ steradians. With appropriate physical shielding, the real Published by Elsevier. This is the Author Accepted Manuscript issued with: Creative Commons Attribution Non-Commercial Licence (CC:BY:NC 4.0). The final published version (version of record) is available online at DOI: 10.1016/j.nima.2018.07.049. Please refer to any applicable publisher terms of use. 
Nuclear Instruments and Methods in Physics Research Section A: Accelerators, Spectrometers, Detectors and Associated Equipment Volume 905, 11 October 2018, Pages 119-128

https://doi.org/10.1016/j.nima.2018.07.049

camera response should not be significantly different from the theoretical case. Secondly, real scattering from a test object occurs predominantly from the object's surface, whilst the theoretical test object generates photons from throughout its thickness. Although this could have a minor influence on the apparent width of the wire, it is the superior counting statistics of the emitter approach used consistently that is most useful.

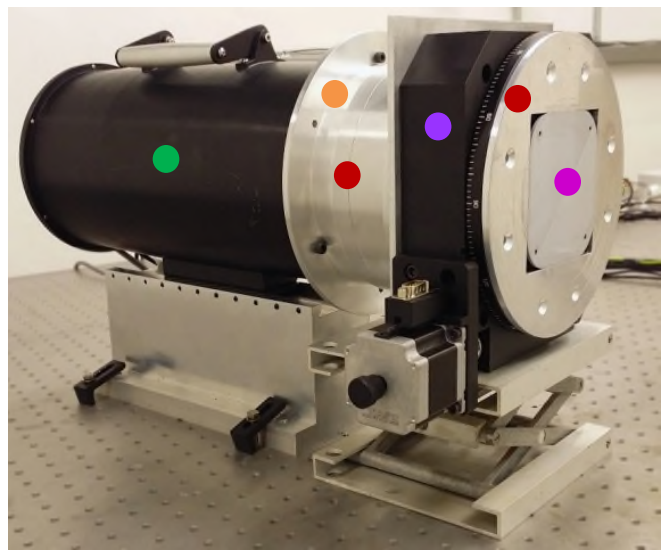

(a)

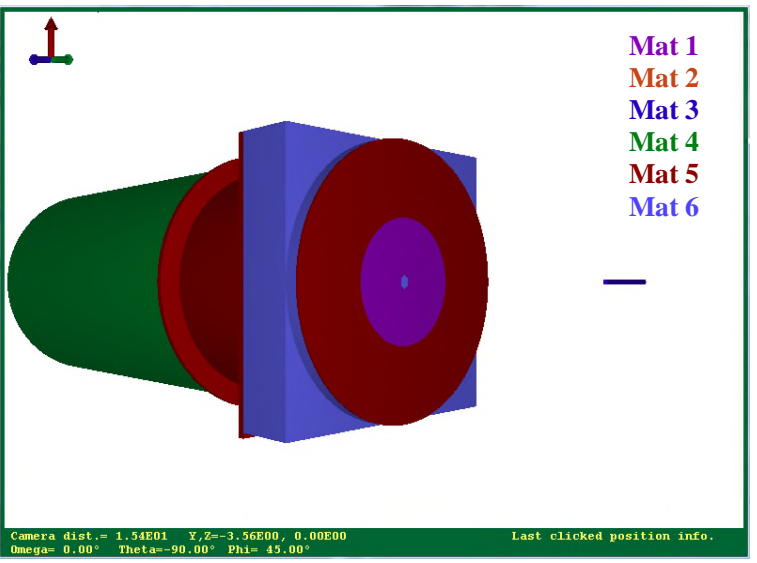

(b)

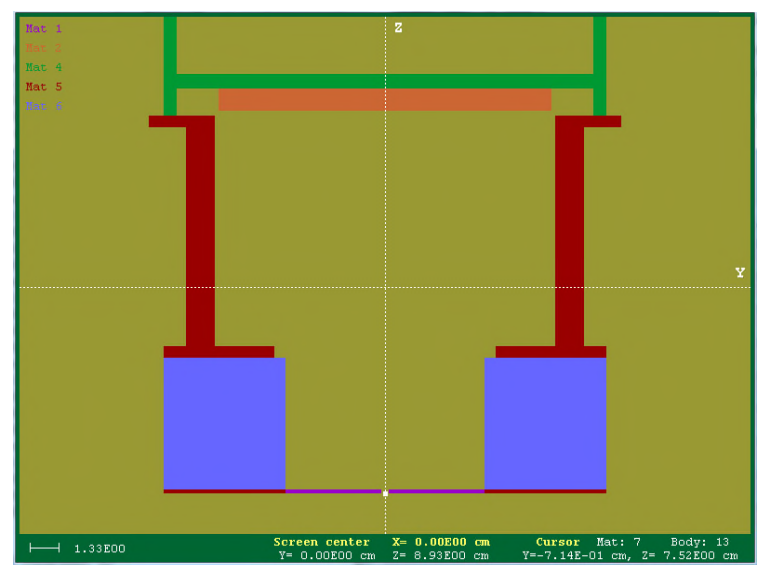

(c)

Figure 1 (a) shows the X-Ray camera in the experimental setup, (b) shows the PENGEOM model in 3D. (c) is a cross section showing the position of the detector inside the shielding. The following components can be seen in $1 \mathrm{~b}$ and $1 \mathrm{c}$ with the PENGEOM colour code:

pinhole mask (W, W Ep. Or Bi All.), in purple, rotation disk, placed in front in front (Al), in red, rotation stage (brass), in light blue, extension $(\mathrm{Al})$, in red, external cylindrical envelopment $(\mathrm{Pb})$, in green, $\mathrm{CCD}$ detector $(\mathrm{Si})$, in orange, wire test object (metal) in dark blue.

Published by Elsevier. This is the Author Accepted Manuscript issued with: Creative Commons Attribution Non-Commercial Licence (CC:BY:NC 4.0). The final published version (version of record) is available online at DOI: 10.1016/j.nima.2018.07.049. Please refer to any applicable publisher terms of use. 
Nuclear Instruments and Methods in Physics Research Section A: Accelerators, Spectrometers, Detectors and Associated Equipment Volume 905, 11 October 2018, Pages 119-128

https://doi.org/10.1016/j.nima.2018.07.049

\subsection{Pinholes and mask materials}

Masks between 0.5 and $10 \mathrm{~mm}$ thickness were studied, with circular straight edge pinholes of 0 (no pinhole) 1, 2 and $3 \mathrm{~mm}$ diameter. The work of Metzler and Bowsher illustrates chamfered edge pinholes [12], but chamfered edges are less common, more difficult to manufacture and would unlikely to be viable to use in numbers suitable for coded apertures. Their existence should be noted, but this work concentrates on straight edge pinholes.

The mask materials investigated were:

- solid tungsten metal, which is difficult to machine,

- tungsten epoxy composite, which can be easily cold cast into complex shapes,

- low melting point bismuth alloy, which can be cast at moderately elevated temperatures.

The density of the mixed tungsten-epoxy composite is about half that of tungsten because of the comparatively large volume taken up by the low-density epoxy resin, as well as a small amount of trapped air. The compositions and mass densities are given in table 1 below.

Table 1 Materials and their chemical composition in \%wt and density in $\mathrm{g} \cdot \mathrm{cm}^{-3}$.

\begin{tabular}{|l|c|c|}
\hline \multicolumn{1}{|c|}{ Materials } & Composition (\%wt) & Density $\left(\mathbf{g ~ c m}^{-\mathbf{3}}\right)$ \\
\hline Tungsten metal & W 100 & 19.6 \\
\hline Tungsten-epoxy composite & W 93.5 & 9.5 \\
& Epoxy A 5.4 & \\
\hline Epoxy B 1.1 & 8.6 \\
\hline Bismuth low-melting point & Bi 56 & \\
alloy & Sn 26 & \\
& In 17 & \\
\hline
\end{tabular}

The three chosen materials were used for manufacturing pinhole and coded aperture masks for performing in a backscatter imaging system in use at Cranfield University [8].

\section{Results}

\subsection{Energy spectra through the mask materials}

Photon transmission through the material of the mask reduces the contrast and increases noise in images produced using pinhole or coded aperture optics [4] [13]. This section Published by Elsevier. This is the Author Accepted Manuscript issued with: Creative Commons Attribution Non-Commercial Licence (CC:BY:NC 4.0). The final published version (version of record) is available online at DOI: 10.1016/j.nima.2018.07.049. Please refer to any applicable publisher terms of use. 
Nuclear Instruments and Methods in Physics Research Section A: Accelerators, Spectrometers, Detectors and Associated Equipment Volume 905, 11 October 2018, Pages 119-128

https://doi.org/10.1016/j.nima.2018.07.049

assesses the capacity of nine masks (without pinholes) to prevent photons from the X-ray emitting wire reaching the detector. The number of photons emitted from the wire was set to $10^{7}$, to achieve acceptable statistics in a relatively short time. Although some of the following figures appear noisy, this is because they show the energy deposited into each pixel to expose our method. The calculations of image characteristics such as spatial resolution and contrast are deduced from many pixels, which makes the statistics acceptable.

The simulated results generated by PENMAIN are recorded in the phase-space file captured at the CCD camera (see in orange in figure 1c). The phase-space file contains diverse useful information including the position, direction and energy of each photon that strikes the model detector. The energy spectra are deduced from the phase-space file by tallying all the photons falling in each energy bin. The quantity of 'probability/keV' refers to the fraction of photons in each $\mathrm{keV}$ width energy bin that reach the detector per $0.1 \mathrm{keV}$ bin. The photon energy spectra through/from the thin $0.5 \mathrm{~mm}$ thickness masks are shown in figure 2.

The spectra show several characteristic features linked to mask material properties. Drops in mask transmission at around 70 and $90 \mathrm{keV}$ are caused by the tungsten and bismuth $\mathrm{K}$ absorption edges, and sharp peaks are caused by fluorescence generated within the masks. Although the absorption cross section of materials generally falls with increased photon energy, there are abrupt rises at absorption edges. A fluorescence photon is less energetic than the incident photon that produced it through electron excitation. When they lie closely either side of a strong absorption edge, then the lower energy fluorescent photon can be more penetrating than the higher energy incident photon that generated it. Further, if the application involves characterising the materials of a distant object through a small pinhole, then even signals generated strongly by that object could be obfuscated by weak fluorescence across a wide mask close to the detector, especially if the energy dispersive detector has poor spatial resolution. Photons caused by fluorescence are an important feature, as their existence means the ideal mask property should not just prevent incident photons being transmitted, but also that it should not generate secondary photons either. 
Nuclear Instruments and Methods in Physics Research Section A: Accelerators, Spectrometers, Detectors and Associated Equipment Volume 905, 11 October 2018, Pages 119-128

https://doi.org/10.1016/j.nima.2018.07.049

For this study, the upper photon energy was set to $200 \mathrm{keV}$ because this is approximately the practical ceiling of many current compact X-ray generators. If these masks were used for imaging photons with significantly higher energy, then there would be a large increase in transmission through the bulk of the mask and image contrast would decrease significantly. Contrast would be further reduced by increased fluorescence from the mask, and there would be a slight degradation in spatial resolution as pinhole edges impacted by photons obliquely would become particularly transparent.

\subsection{Introducing a pinhole and adapting the phase-space file to replicate an imaging plate.}

The phase space file (PSF) contains the energy and position data of each photon hitting the detector [1]. This file can be represented as a three-dimensional energy-scatter plot, (e.g. figure 3a). However, this does not inherently replicate images in the same way as sensors capture images. Sensors do not log impacts from individual photons at precise locations but instead they measure deposited energy over a time period within digitised spatial regions. For the PSF to be presented as an image, the raw data needs to be processed in a similar way to how the detector actually works; i.e. by integrating the energies of all photons hitting each particular pixel over some exposure period. The integrated energy $\mathrm{I}(\mathrm{E})$ seen in fig $3 \mathrm{~b}$ is defined as the sum of the energy of the photon data in the phase space file correlated with the positions and areas of the $1040 \times 1392$ pixels of the real detector. A MATLAB routine was written to accomplish this mapping and integration. Maps were constructed and show how the integrated energy varies at $x-y$ positions across the surface of the detector (see figure $3 b$ ). The images in figure 3 are based on a $4 \mathrm{~mm}$ thick tungsten plate with $2 \mathrm{~mm}$ pinhole equidistant from the test object and detector to give a magnification equal to 1 .

Published by Elsevier. This is the Author Accepted Manuscript issued with: Creative Commons Attribution Non-Commercial Licence (CC:BY:NC 4.0). The final published version (version of record) is available online at DOI: 10.1016/j.nima.2018.07.049. Please refer to any applicable publisher terms of use. 
Nuclear Instruments and Methods in Physics Research Section A: Accelerators, Spectrometers, Detectors and Associated Equipment Volume 905, 11 October 2018, Pages 119-128

https://doi.org/10.1016/j.nima.2018.07.049

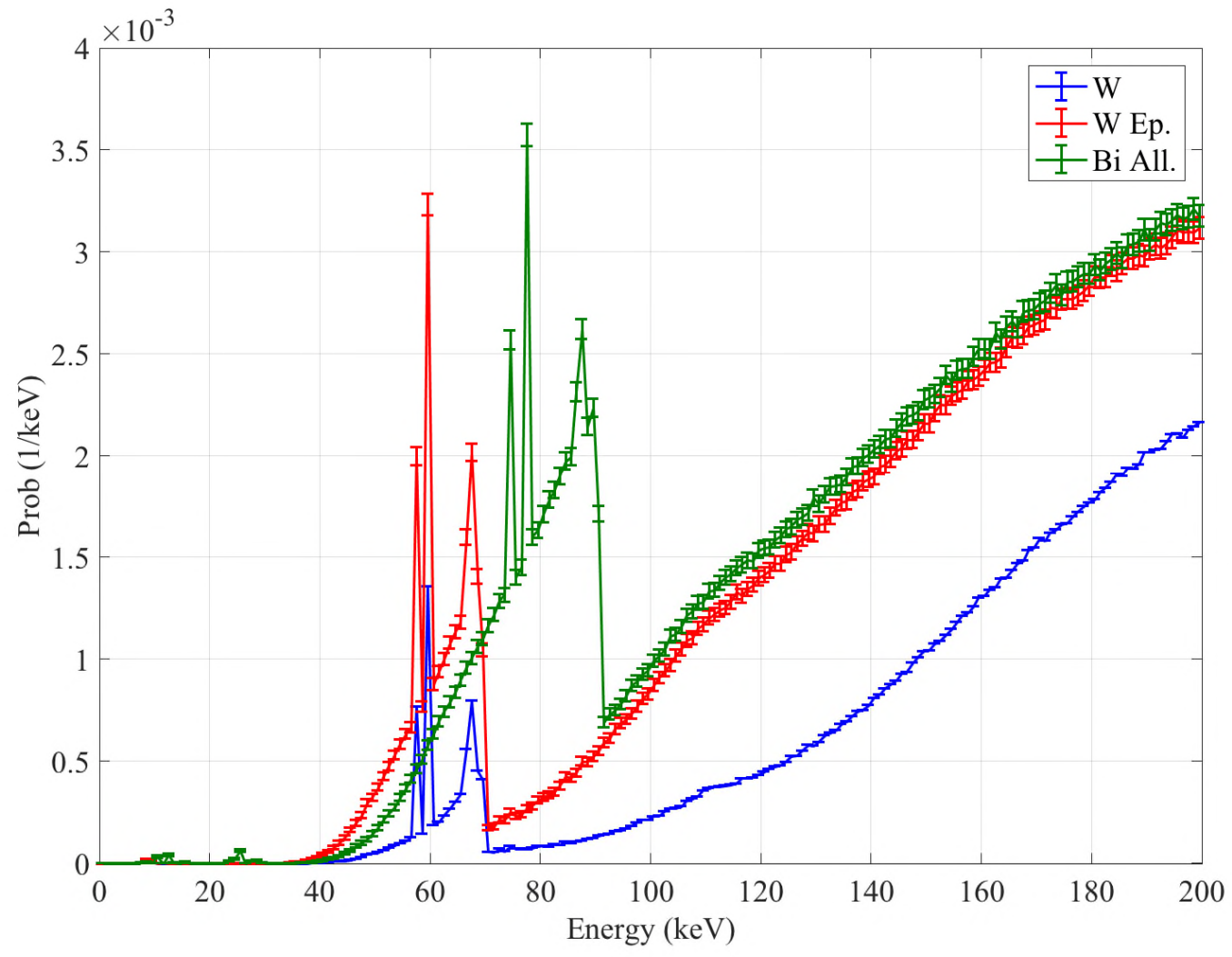

Figure 2 The photon energy-probability spectrum for $0.5 \mathrm{~mm}$ thickness masks for $\mathrm{W}$, W Epoxy composite and Bi alloy masks without a pinhole [13]. Spectra were tallied at the detector (in orange in figure 1c), behind the pinhole mask (in purple in figure 1b-c) and shielded by a lead-aluminium cylinder (in green in figure $1 \mathrm{~b}-\mathrm{c}$ ).

\subsection{Preliminary appraisal of contrast and field of view with pinhole masks of different thicknesses}

The integrated energy images of the test wire from three mask materials at different thicknesses were simulated to appraise the influence of pinhole mask properties on image contrast and field of view. Figure 4 compares the effect of increasing the thickness for pure tungsten using a $1 \mathrm{~mm}$ aperture. At $1 \mathrm{~mm}$ thickness (fig. $4 \mathrm{a}$ ) there is significant transmission through tungsten and the image appears noisy. At $2 \mathrm{~mm}$ thickness pure tungsten (fig. $4 \mathrm{~b}$ ) prevents enough photons from penetrating the mask body so that photons that travel through Published by Elsevier. This is the Author Accepted Manuscript issued with: Creative Commons Attribution Non-Commercial Licence (CC:BY:NC 4.0). The final published version (version of record) is available online at DOI: 10.1016/j.nima.2018.07.049. Please refer to any applicable publisher terms of use. 
Nuclear Instruments and Methods in Physics Research Section A: Accelerators, Spectrometers, Detectors and Associated Equipment Volume 905, 11 October 2018, Pages 119-128

https://doi.org/10.1016/j.nima.2018.07.049

the pinhole from the object can be seen clearly above the low background noise. At $4 \mathrm{~mm}$ thickness (fig. 4c) the tungsten appears to be an effective mask, but the imaged wire is not observable over its full length. At $10 \mathrm{~mm}$, the background has been reduced to zero, but the ends of the wire cannot be seen, indicating collimation (see figure 4d). The change of colours along the test object in figure 4 reveal how the collimation effect increases with mask thickness. The centre pixel should be unaffected by mask thickness, however fluorescence and scatter off the inner walls off a pinhole will have some influence.

Large apertures admit more photons than small ones, with exposure time reducing nominally as the square of the diameter. Thus, the diameter was increased. Images were simulated and examined at $1 \mathrm{~mm}, 2 \mathrm{~mm}$ and $3 \mathrm{~mm}$ aperture diameter in masks up to $10 \mathrm{~mm}$ thickness. An example of 1 to $3 \mathrm{~mm}$ aperture diameters in pinhole mask is given in figure 5 for $2 \mathrm{~mm}$ thickness pure tungsten. Figure 6 shows the preliminary findings for $2 \mathrm{~mm}$ aperture pinholes in $2 \mathrm{~mm}$ thick pure tungsten and two alternative materials twice as thick. Tungsten-epoxy and bismuth alloy are candidate mask materials because they can be manufactured into coded apertures easily [8]. Whilst tungsten appears to give acceptable images at $2 \mathrm{~mm}$ thickness (fig. 6a), tungsten-epoxy (fig. 6b) and bismuth alloy (fig. 6c) gave equivalent images at $4 \mathrm{~mm}$ thickness when a $2 \mathrm{~mm}$ diameter aperture is used. These are the thinnest lightest combinations that reduce background to a subjectively reasonable level for this energy range of photons.

Published by Elsevier. This is the Author Accepted Manuscript issued with: Creative Commons Attribution Non-Commercial Licence (CC:BY:NC 4.0). The final published version (version of record) is available online at DOI: 10.1016/j.nima.2018.07.049. Please refer to any applicable publisher terms of use. 
Nuclear Instruments and Methods in Physics Research Section A: Accelerators, Spectrometers, Detectors and Associated Equipment Volume 905, 11 October 2018, Pages 119-128

https://doi.org/10.1016/j.nima.2018.07.049

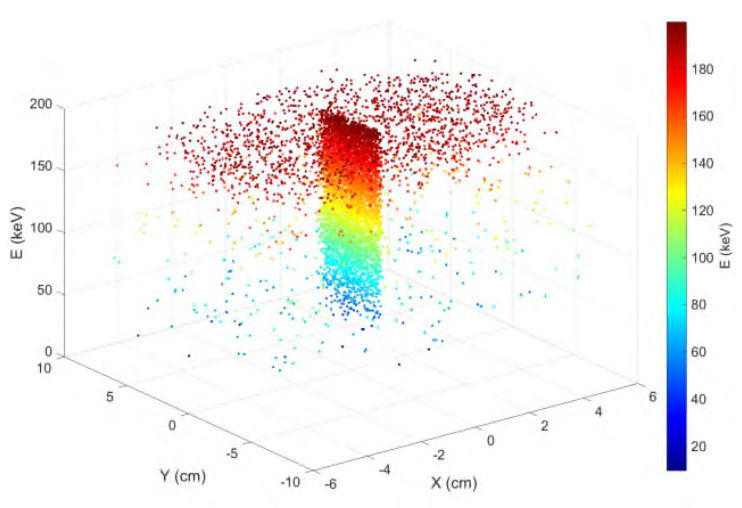

(a)

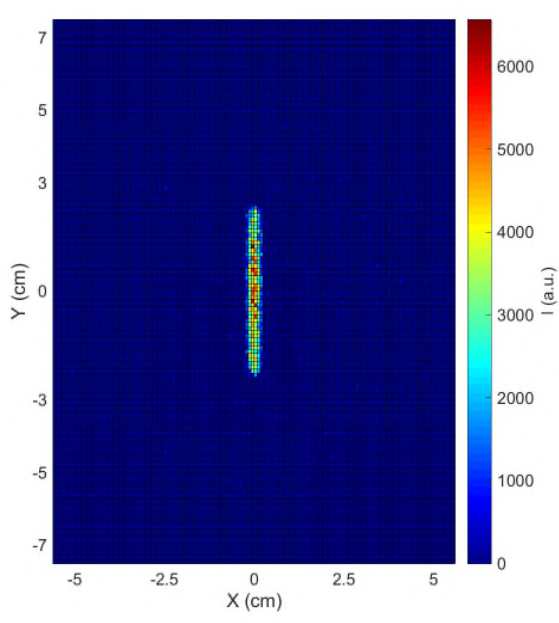

(b)

Figure 3 (a) is a scatter plot of the energy of each photon incident on the detector for a $4 \mathrm{~mm}$ thickness $\mathrm{W}$ mask with a $2 \mathrm{~mm}$ diameter aperture (colour scale energy in $\mathrm{keV}$ ). Fig (b) shows the same integrated energy per pixel presented in 2D to reflect the brightness of an image.

Published by Elsevier. This is the Author Accepted Manuscript issued with: Creative Commons Attribution Non-Commercial Licence (CC:BY:NC 4.0). The final published version (version of record) is available online at DOI: 10.1016/j.nima.2018.07.049. Please refer to any applicable publisher terms of use. 
Nuclear Instruments and Methods in Physics Research Section A: Accelerators, Spectrometers, Detectors and Associated Equipment Volume 905, 11 October 2018, Pages 119-128

https://doi.org/10.1016/j.nima.2018.07.049

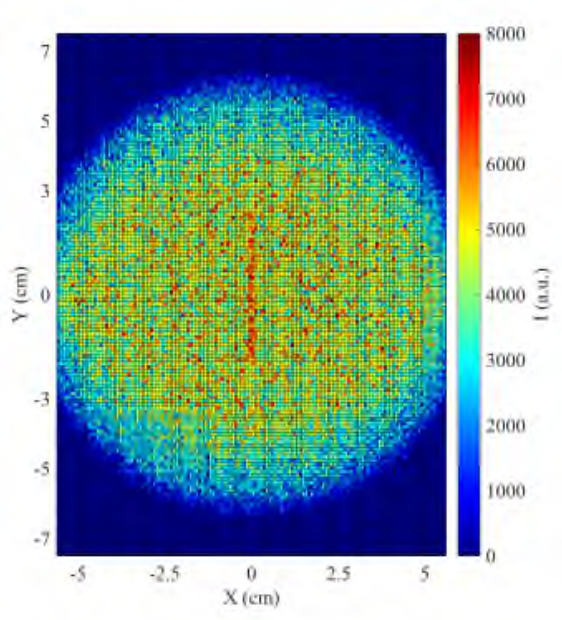

(a)

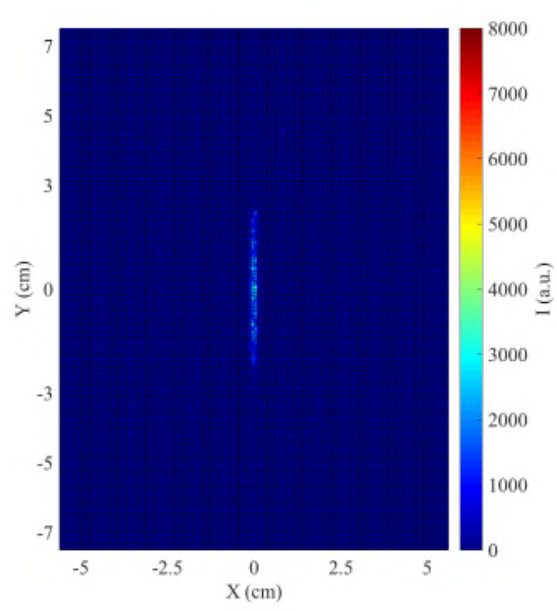

(c)

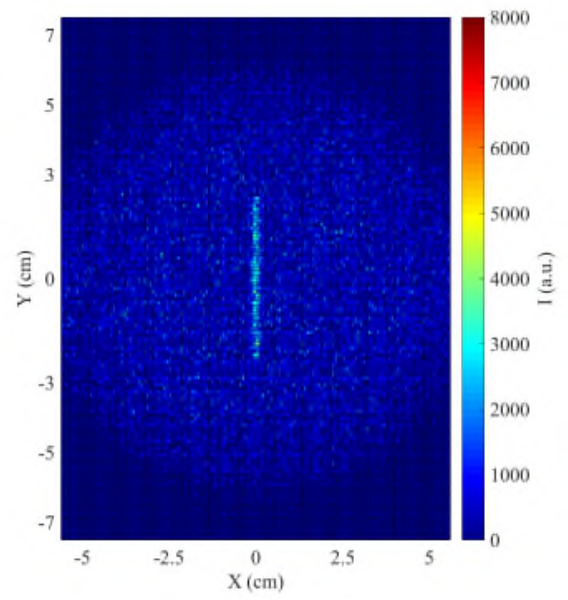

(b)

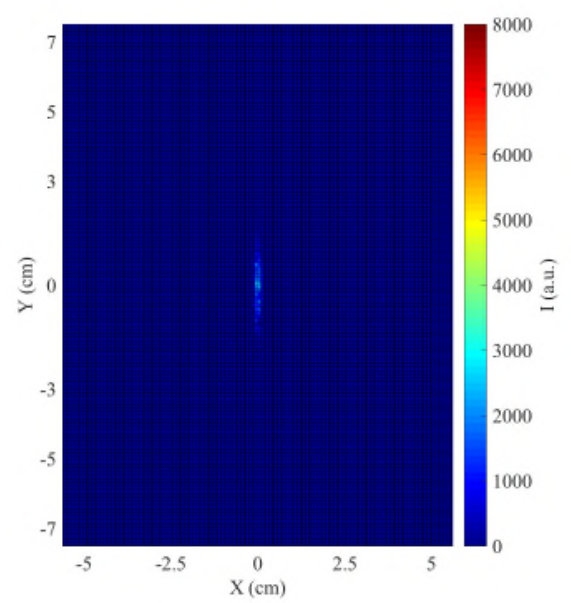

(d)

Figure 4 Image of 0-200 $\mathrm{keV}$ photons through pure tungsten for a $1 \mathrm{~mm}$ aperture diameter and (a) 1 $\mathrm{mm}$ thickness, (b) $2 \mathrm{~mm}$ thickness, (c) $4 \mathrm{~mm}$ thickness and (d) $10 \mathrm{~mm}$ thickness. At $10 \mathrm{~mm}$ thickness, only the central area of the ROI is detected, and the detected wire appears cropped.

Published by Elsevier. This is the Author Accepted Manuscript issued with: Creative Commons Attribution Non-Commercial Licence (CC:BY:NC 4.0). The final published version (version of record) is available online at DOI: 10.1016/j.nima.2018.07.049. Please refer to any applicable publisher terms of use. 
Nuclear Instruments and Methods in Physics Research Section A: Accelerators, Spectrometers, Detectors and Associated Equipment Volume 905, 11 October 2018, Pages 119-128

https://doi.org/10.1016/j.nima.2018.07.049

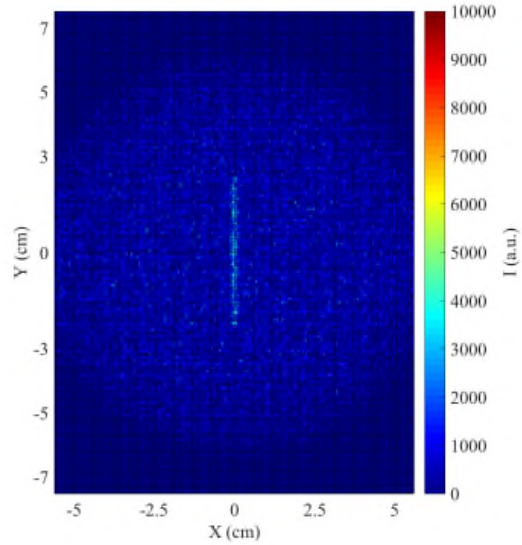

(a)

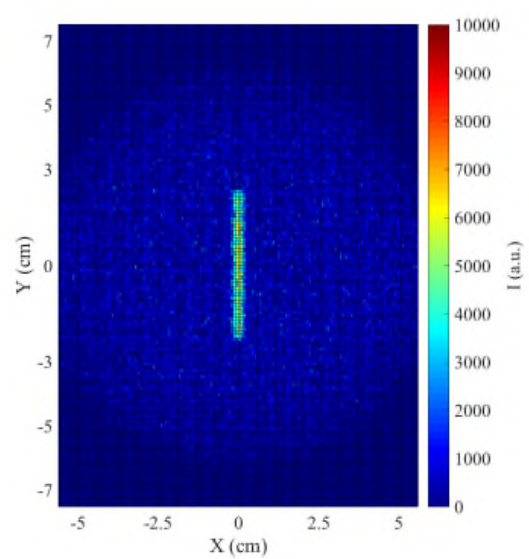

(b)

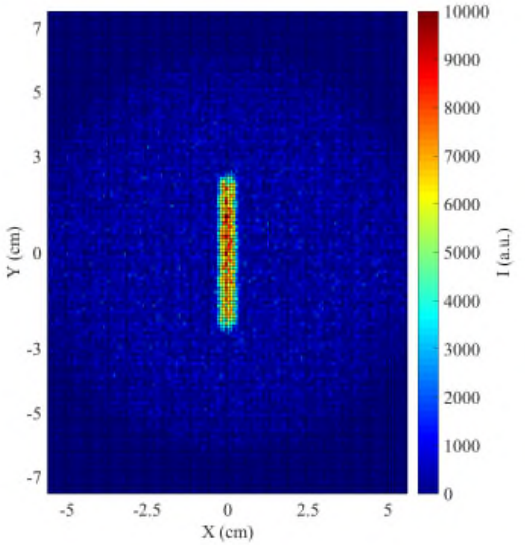

(c)

Figure 5 (a) Image of 0-200 keV photons through pure tungsten for a $2 \mathrm{~mm}$ thickness and (a) $1 \mathrm{~mm}$ aperture diameter, (b) $2 \mathrm{~mm}$ aperture diameter, (c) $3 \mathrm{~mm}$ aperture diameter. Note large apertures (3c) admit more photons than small ones (3a, 3b).

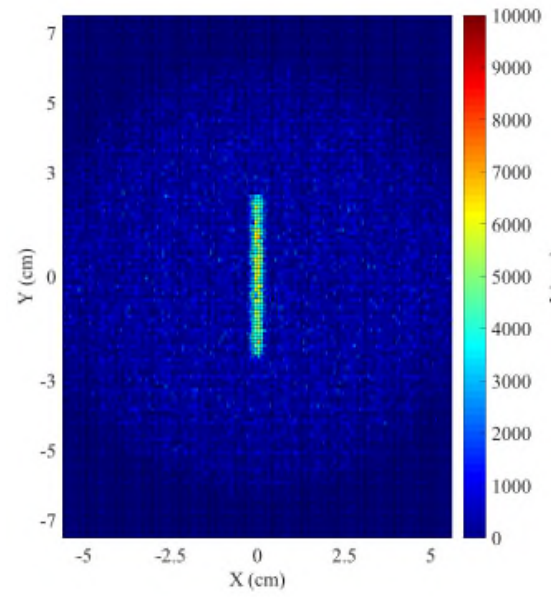

(a)

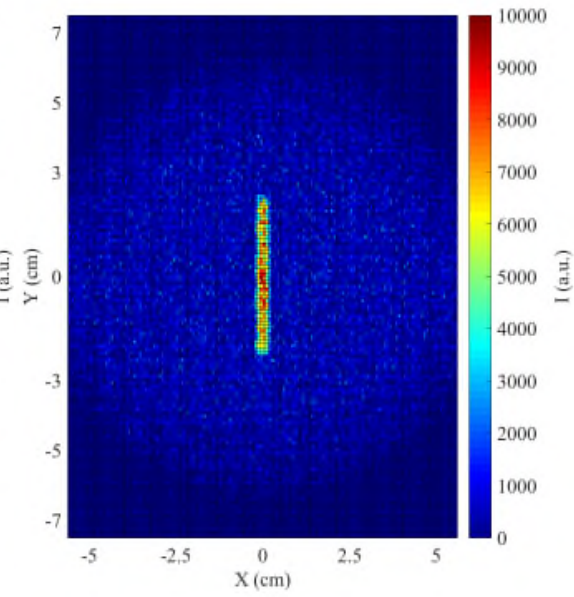

(b)

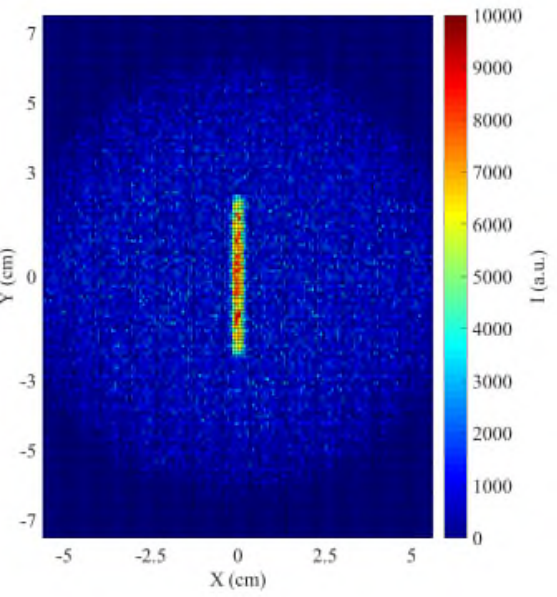

(c)

Figure 6 Image of 0-200 keV photons through a) pure tungsten for thickness $2 \mathrm{~mm}$, b) W Epoxy for thickness $4 \mathrm{~mm}$, and c) Bi alloy for thickness $4 \mathrm{~mm}$.

\subsection{Determining the ROI}

The geometry of the simulation was set to give an image size equal to the $46 \mathrm{~mm} \times 0.3 \mathrm{~mm}$ test object. The object image should ideally fully occupy and be confined to the pixels that correspond to the source dimensions as the magnification is equal to unity. However finite Published by Elsevier. This is the Author Accepted Manuscript issued with: Creative Commons Attribution Non-Commercial Licence (CC:BY:NC 4.0). The final published version (version of record) is available online at DOI: 10.1016/j.nima.2018.07.049. Please refer to any applicable publisher terms of use. 
Nuclear Instruments and Methods in Physics Research Section A: Accelerators, Spectrometers, Detectors and Associated Equipment Volume 905, 11 October 2018, Pages 119-128

https://doi.org/10.1016/j.nima.2018.07.049

resolution broadens the image beyond these confines. The limits of the Region Of Interest (ROI) were thus set $-23 \leq \mathrm{y} \leq 23 \mathrm{~mm}$ and $-2 \leq \mathrm{x} \leq 2 \mathrm{~mm}$ for the smallest aperture, but the horizontal $\mathrm{x}$-axis ROI parameters were raised for larger apertures to ensure image broadening was accommodated. These limits were set on MATLAB for extraction of the ROI against the image background. Once ROI is determined, the background noise was estimated as the whole image integrated energy minus the ROI. An example of the applied method is shown in figure 7: a) is the whole image, b) is the identified ROI and c) is the background noise.

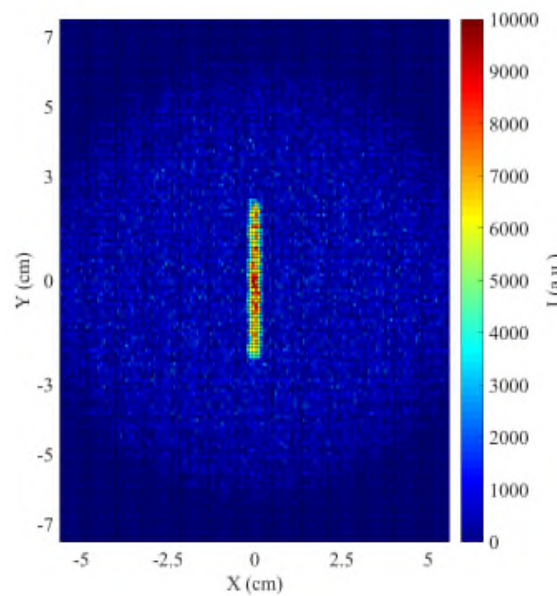

(a)

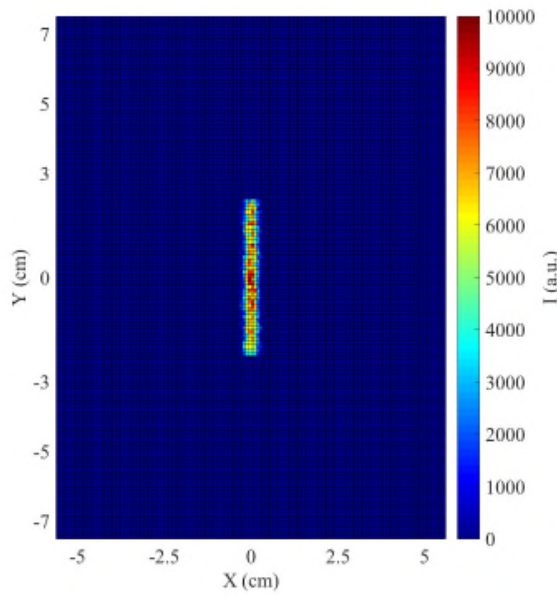

(b)

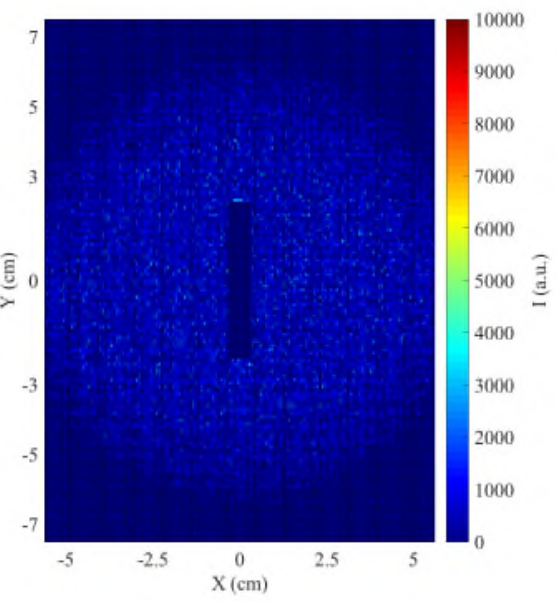

(c)

Figure 7 Image obtained from test wire using a $2 \mathrm{~mm}$ aperture in $2 \mathrm{~mm} \mathrm{~W}$ epoxy. (a) represents the whole image, (b) just the area closely surrounding where the test object signal should geometrically lie, (c) the background region only.

\subsection{Spatial resolution}

Generally, spatial resolution is a metric to quantify the ability of an imaging system to distinguish between two unique objects closely separated in space [14]. The resolution is normally measured by imaging test objects with decreasing separations of parallel lines [15]. Another way to quantify resolution is by defining it in terms of the observed full width at half maximum (FWHM) of a single infinitely narrow object or an infinitely abrupt edge feature. In our case, the FWHM method has been applied across the thin test object where the image Published by Elsevier. This is the Author Accepted Manuscript issued with: Creative Commons Attribution Non-Commercial Licence (CC:BY:NC 4.0). The final published version (version of record) is available online at DOI: 10.1016/j.nima.2018.07.049. Please refer to any applicable publisher terms of use. 
Nuclear Instruments and Methods in Physics Research Section A: Accelerators, Spectrometers, Detectors and Associated Equipment Volume 905, 11 October 2018, Pages 119-128

https://doi.org/10.1016/j.nima.2018.07.049

intensity in the $\mathrm{x}$ direction of the Region of Interest (ROI) shows a Gaussian profile. An example image of the test object can be seen in Fig 8a. Although the FWHM along the x-axis is used to determine the resolution, the sum of the integrated energy down the y direction columns is used to maximise counting statistics. The column sum as a function of $\mathrm{x}$ is shown in Fig 8b, where a Gaussian fit is applied to determine the FWHM. The graphs on figures 9 and 10 show how the FWHM varies with aperture diameter and mask thickness.

\subsection{Spatial resolution as function of aperture diameter and thickness}

Generally, the resolution improves (i.e. FWHM reduces) with reducing pinhole diameter. Pinhole masks were also simulated at narrower apertures, such as $0.1 \mathrm{~mm}$ and $0.5 \mathrm{~mm}$, and wider apertures such as $6 \mathrm{~mm}$ and $10 \mathrm{~mm}$. The effect of the resolution as FWHM against the aperture diameter can be seen in figure 9. As the FWHM decreases, the resolution increases. However, due to the pixel size limitation, there is a plateau between $0.1 \mathrm{~mm}$ and $1 \mathrm{~mm}$ aperture diameter for all the three materials.

On the other hand, the resolution reduces slightly with increasing mask thickness for the same aperture diameter. This is because thin masks allow large numbers of X-rays to be transmitted through the aperture edges obliquely which effectively increases the diameter of the aperture, whilst thick masks only allow X-rays that hit the mask aperture perpendicularly to pass (collimation). In figure 10, pure tungsten, tungsten-epoxy and bismuth alloy FWHMs were compared against the thickness. For the thin mask thicknesses tested here the same spatial resolution achieved by tungsten-epoxy and bismuth alloy can be achieved by half the thickness of pure tungsten because of its low transmission.

Published by Elsevier. This is the Author Accepted Manuscript issued with: Creative Commons Attribution Non-Commercial Licence (CC:BY:NC 4.0). The final published version (version of record) is available online at DOI: 10.1016/j.nima.2018.07.049. Please refer to any applicable publisher terms of use. 
Nuclear Instruments and Methods in Physics Research Section A: Accelerators, Spectrometers, Detectors and Associated Equipment Volume 905, 11 October 2018, Pages 119-128

https://doi.org/10.1016/j.nima.2018.07.049

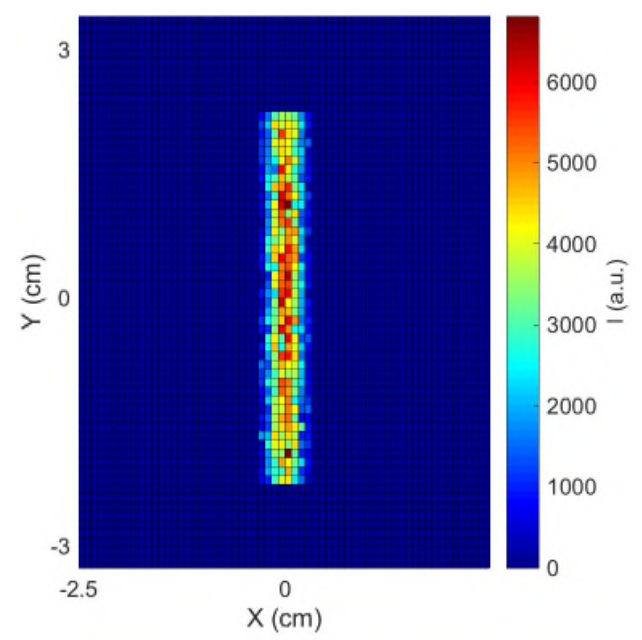

(a)

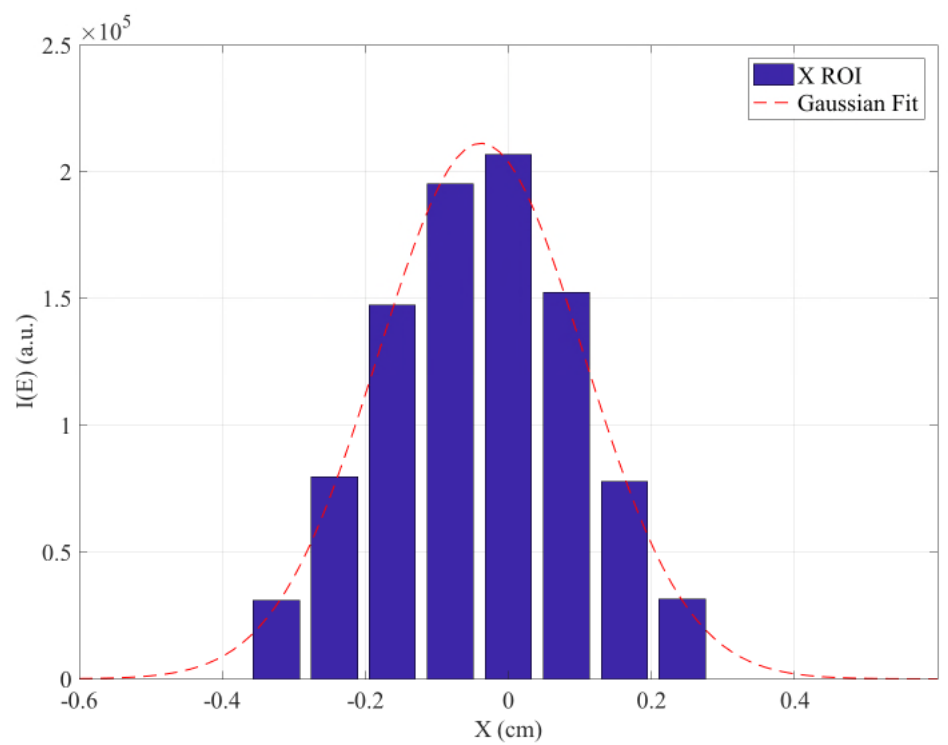

(b)

Figure 8 Image of the test object for a $2 \mathrm{~mm}$ thick $2 \mathrm{~mm}$ aperture tungsten pinhole mask (a) and the summed y-column pixels across the thin x-axis (maximum uncertainty $\pm 0.87 \cdot 10^{3}$ ) (b). A Gaussian fit has been plotted on the histogram to calculate the FWHM (red line).

Published by Elsevier. This is the Author Accepted Manuscript issued with: Creative Commons Attribution Non-Commercial Licence (CC:BY:NC 4.0). The final published version (version of record) is available online at DOI: 10.1016/j.nima.2018.07.049. Please refer to any applicable publisher terms of use. 
Nuclear Instruments and Methods in Physics Research Section A: Accelerators, Spectrometers, Detectors and Associated Equipment Volume 905, 11 October 2018, Pages 119-128

https://doi.org/10.1016/j.nima.2018.07.049

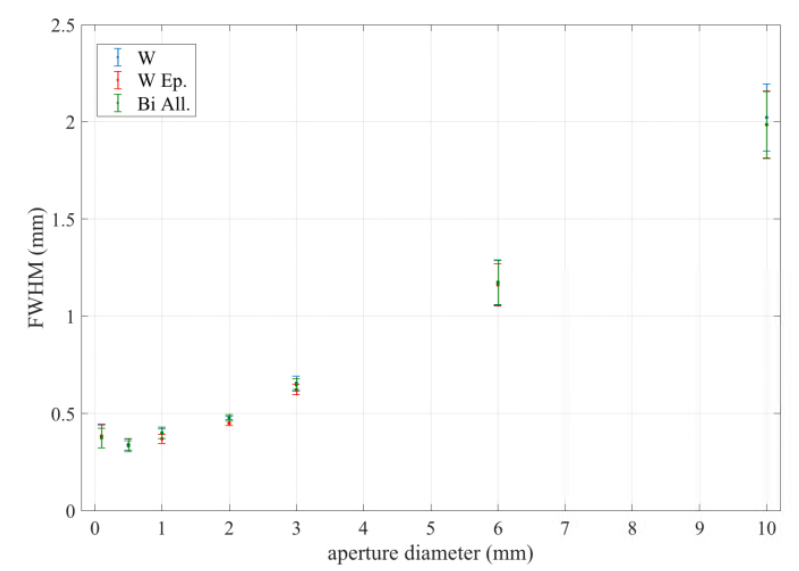

Figure 9 The image spatial resolution available for pinhole masks of different apertures and materials and $2 \mathrm{~mm}$ thickness pure tungsten and $4 \mathrm{~mm}$ thickness tungsten-epoxy resin and bismuth alloy.

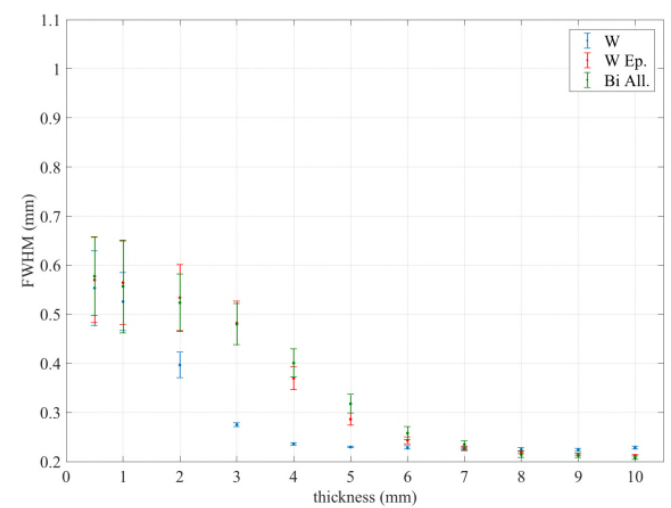

(a)

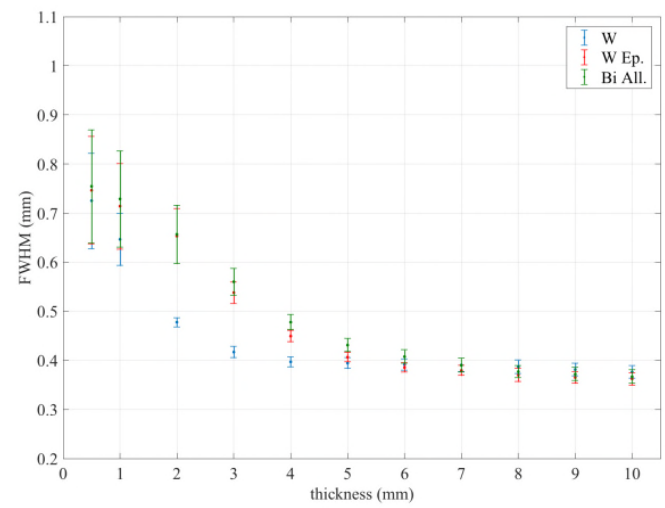

(b)

Published by Elsevier. This is the Author Accepted Manuscript issued with: Creative Commons Attribution Non-Commercial Licence (CC:BY:NC 4.0). The final published version (version of record) is available online at DOI: 10.1016/j.nima.2018.07.049. Please refer to any applicable publisher terms of use. 
Nuclear Instruments and Methods in Physics Research Section A: Accelerators, Spectrometers, Detectors and Associated Equipment Volume 905, 11 October 2018, Pages 119-128

https://doi.org/10.1016/j.nima.2018.07.049

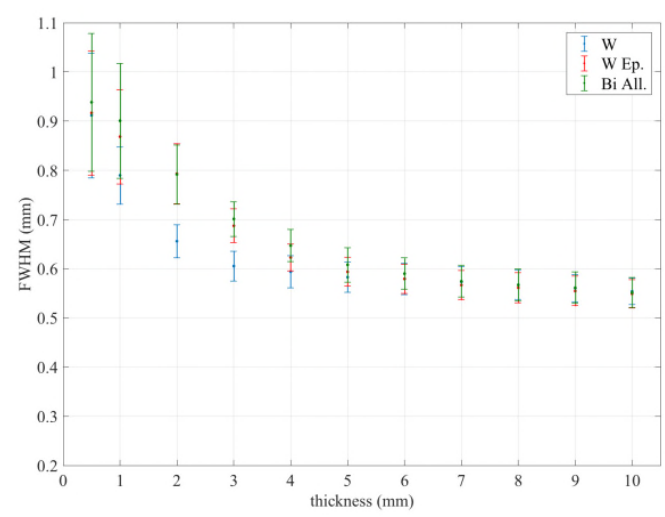

(c)

Figure 10 Image spatial resolution available for pinhole masks of $1 \mathrm{~mm}, 2 \mathrm{~mm}$ and $3 \mathrm{~mm}$ apertures, $0.5-10 \mathrm{~mm}$ thicknesses for $\mathrm{W}, \mathrm{W}$ epoxy, Bi alloy.

\subsection{Estimating the Field of View and Collimation effects}

An ideal pinhole mask would transmit photons through a single locus from across $4 \pi$ steradians. In practice, as the mask thickness increases the acceptance angle and the field of view decrease. Simple pinhole images would thus appear cropped at their edges. This effect is shown in figure 4 but may also be seen in figure 11. Figure 11 is the image of the wire at 2 $\mathrm{mm}$ (a) and $10 \mathrm{~mm}$ (b) thickness at the same aperture diameter $(2 \mathrm{~mm})$ and material (pure tungsten). Images taken with coded apertures would exhibit partial coding and produce artefacts, even if the nominal field of view (FOV) were achieved.

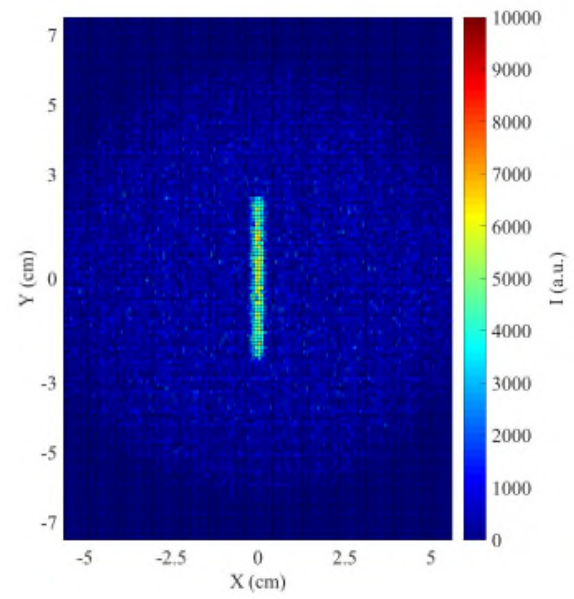

(a)

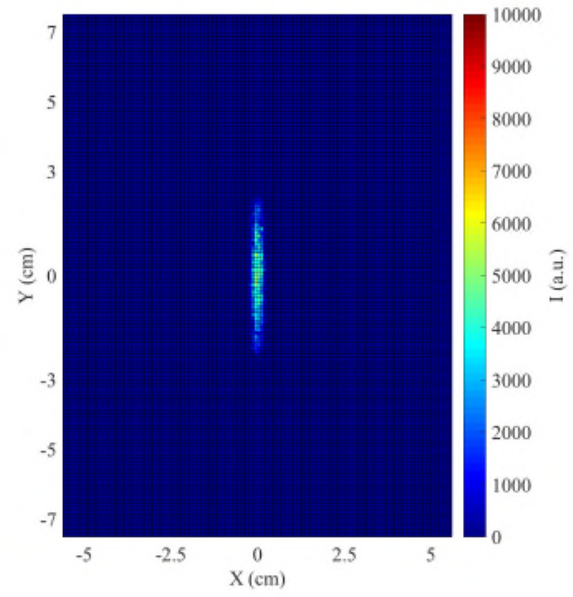

(b)

Published by Elsevier. This is the Author Accepted Manuscript issued with: Creative Commons Attribution Non-Commercial Licence (CC:BY:NC 4.0). The final published version (version of record) is available online at DOI: 10.1016/j.nima.2018.07.049. Please refer to any applicable publisher terms of use. 
Nuclear Instruments and Methods in Physics Research Section A: Accelerators, Spectrometers, Detectors and Associated Equipment Volume 905, 11 October 2018, Pages 119-128

https://doi.org/10.1016/j.nima.2018.07.049

Figure 11 Image of $200 \mathrm{keV}$ photons through pure W for thickness (a) $2 \mathrm{~mm}$ and (b) $10 \mathrm{~mm}$. (b) shows how the effect of the collimation occurs when the mask is thick. The wire is not fully resolved, and edges appear cropped.

The wire test object was designed to be long specifically to evaluate the FOV and collimation effect. Figure $11 \mathrm{~b}$ shows that the wire's image is not cropped abruptly, instead the signal weakens near the ends. A Gaussian fit along the y-axis of the wire's image was used as a simple reproducible measure of its apparent length. Figure 12 shows the collimation effect via the apparent length of the $46 \mathrm{~mm}$ test object, as a function of mask material and thickness. Figure 13 shows the effect as function of aperture size, but as the image plate is $166 \mathrm{~mm}$ from the pinhole then FOV can be expressed in terms of Angle of View (AOV) for general use in other applications. For thin masks with wide apertures the Gaussian fit can extend a little beyond the true length of the wire because of degraded spatial resolution. The collimation effect is observed most strongly for thick pure tungsten masks with narrow apertures. The FOV for small apertures is more sensitive to changes in mask thickness than for large apertures, and similarly the AOV for thick masks is more sensitive to changes in aperture than for thin masks. The data presented is based on a test object centred in the field of view; the consequences could be more extreme for objects which are offset from the centre axis of a pinhole. Only one of the many apertures from a coded aperture can be at the centre so evaluating the consequences of partial coding caused by collimation would not be trivial.

Published by Elsevier. This is the Author Accepted Manuscript issued with: Creative Commons Attribution Non-Commercial Licence (CC:BY:NC 4.0). The final published version (version of record) is available online at DOI: 10.1016/j.nima.2018.07.049. Please refer to any applicable publisher terms of use. 
Nuclear Instruments and Methods in Physics Research Section A: Accelerators, Spectrometers, Detectors and Associated Equipment Volume 905, 11 October 2018, Pages 119-128

https://doi.org/10.1016/j.nima.2018.07.049

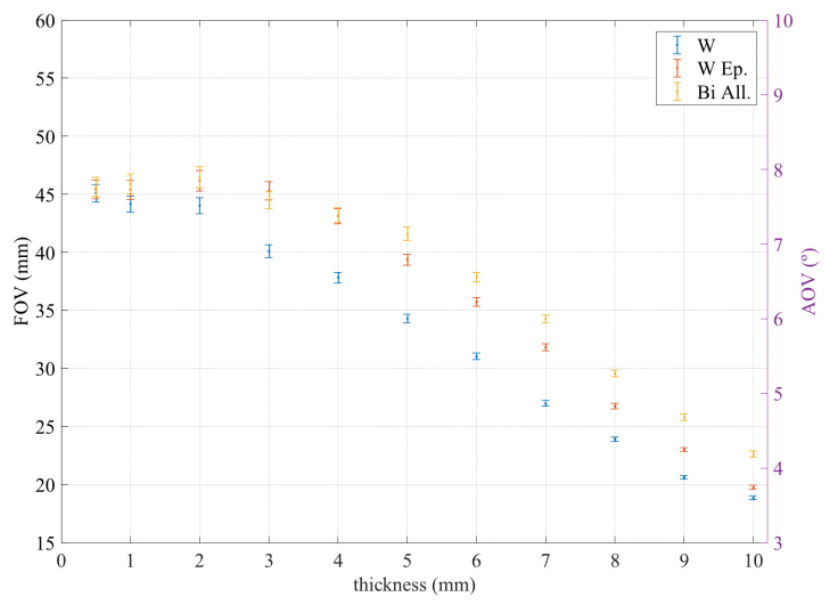

(a)

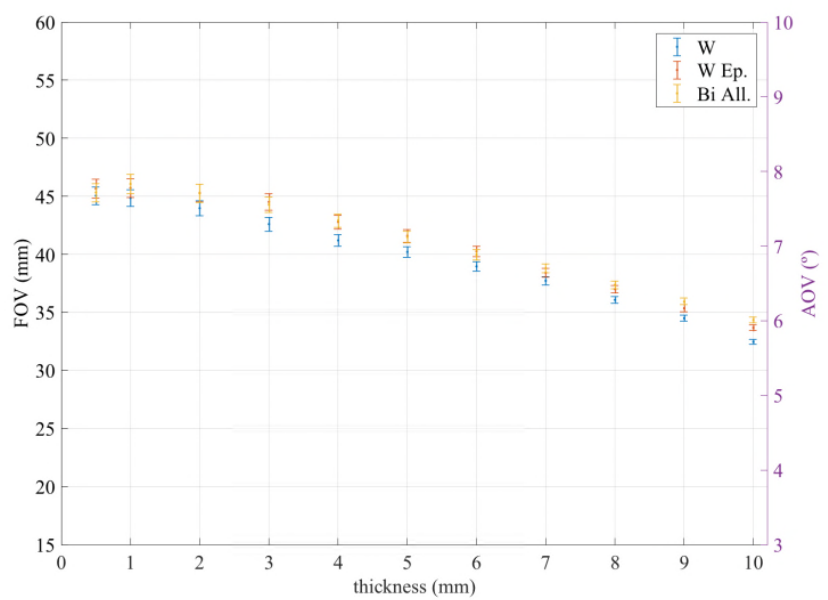

(b)

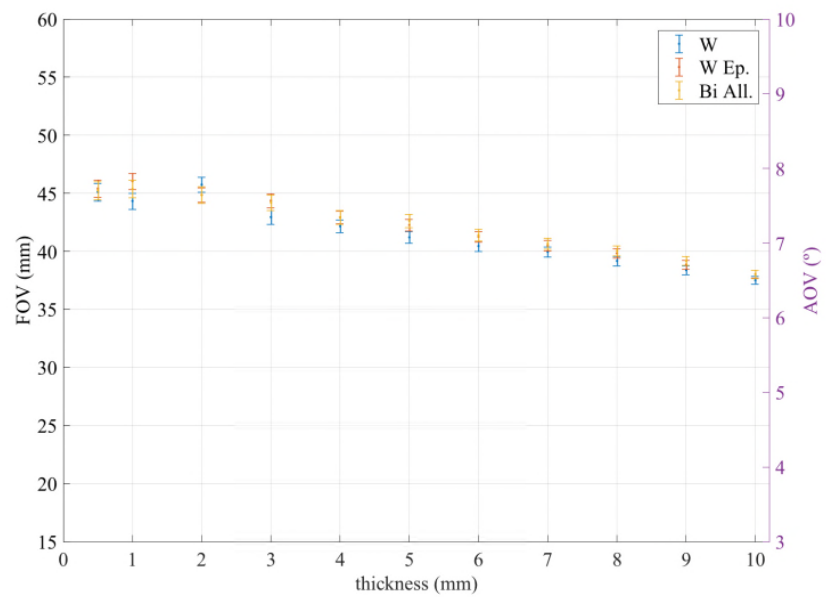

Published by Elsevier. This is the Author Accepted Manuscript issued with: Creative Commons Attribution Non-Commercial Licence (CC:BY:NC 4.0). The final published version (version of record) is available online at DOI: 10.1016/j.nima.2018.07.049. Please refer to any applicable publisher terms of use. 
Nuclear Instruments and Methods in Physics Research Section A: Accelerators, Spectrometers, Detectors and Associated Equipment Volume 905, 11 October 2018, Pages 119-128

https://doi.org/10.1016/j.nima.2018.07.049

(c)

Figure 12 The Field of view in terms of the apparent length (left axis) of a $46 \mathrm{~mm}$ test object as a function of pinhole mask thickness at $1 \mathrm{~mm}$ (a), $2 \mathrm{~mm}$ (b) and $3 \mathrm{~mm}$ (c) aperture diameters.

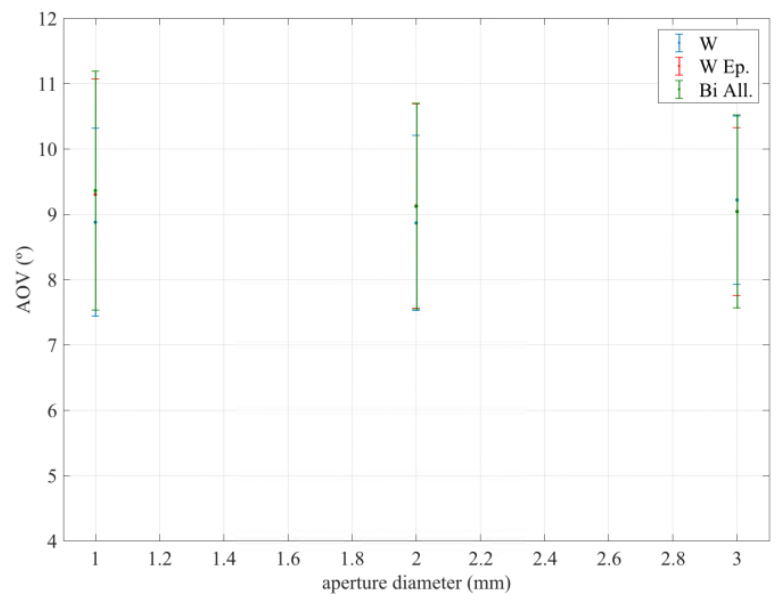

(a)

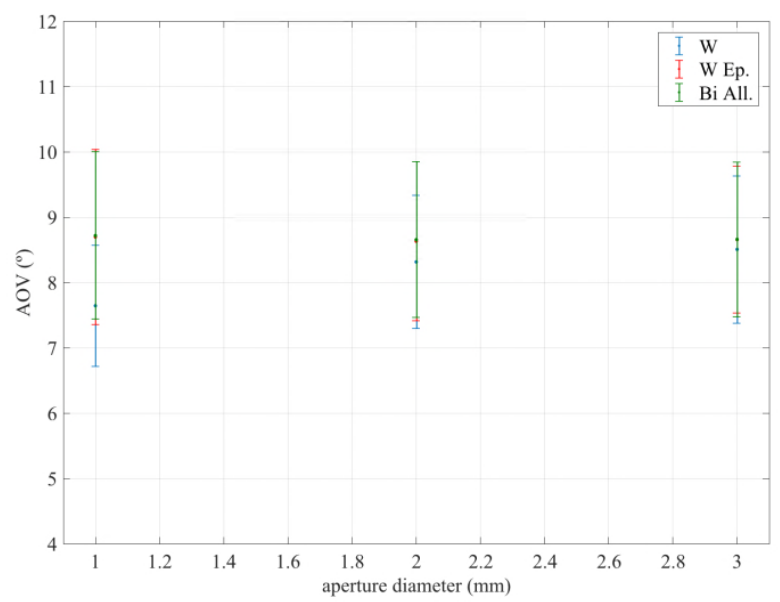

(b)

Published by Elsevier. This is the Author Accepted Manuscript issued with: Creative Commons Attribution Non-Commercial Licence (CC:BY:NC 4.0). The final published version (version of record) is available online at DOI: 10.1016/j.nima.2018.07.049. Please refer to any applicable publisher terms of use. 
Nuclear Instruments and Methods in Physics Research Section A: Accelerators, Spectrometers, Detectors and Associated Equipment Volume 905, 11 October 2018, Pages 119-128

https://doi.org/10.1016/j.nima.2018.07.049

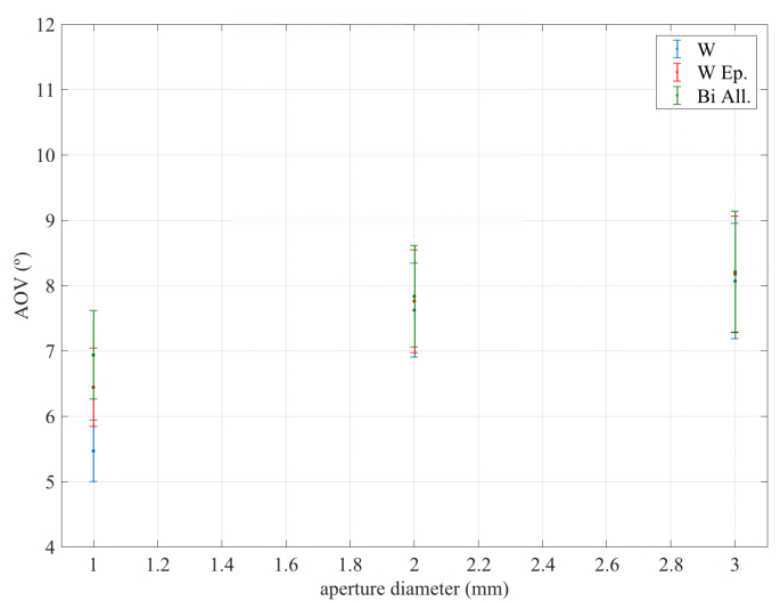

(c)

Figure 13 The Field of View in terms of angle as a function of pinhole mask aperture diameter for $2 \mathrm{~mm}$ (a), $4 \mathrm{~mm}$ (b) and $7 \mathrm{~mm}$ (c) thicknesses.

\section{Conclusion}

This work makes four major contributions; it describes a convenient efficient test object for evaluating X-ray optics, it processes the PENELOPE output into a simulated CCD image, it compactly outlines how image characteristics can be simply and reproducibly quantified, and it gives guidance on suitable materials, thicknesses and apertures for simple pinhole masks. The PENELOPE Monte Carlo simulation suite has been applied to design, test and optimise the optics of an X-ray backscatter imaging system. PENELOPE has proven to be a versatile tool to model our experimental imaging system and to create a virtual test object with characteristics more suited to design and evaluation than could be achieved experimentally.

A long thin X-ray emitting test wire was shown to be an efficient means to simultaneously characterise a range of parameters such as resolution and field of view. The X-ray photons incident on the masks were uniformly distributed between $0.1 \mathrm{keV}$ and $200 \mathrm{keV}$ to make this work more general and not specific to a particular type of generator, target or filtered system. The optimum pinhole will likely be different for different X-ray source spectra. The creation of MATLAB code to convert PENELOPE's phase space file into the spatial 'brightness' that would be seen across a typical pixelated imaging plate extended the utility of PENELOPE 
Nuclear Instruments and Methods in Physics Research Section A: Accelerators, Spectrometers, Detectors and Associated Equipment Volume 905, 11 October 2018, Pages 119-128

https://doi.org/10.1016/j.nima.2018.07.049

from a radiation transport code into modelling existing imaging plate technology. This allowed simulated images to be collected from a systematically changing set of parameters for pinhole masks, such as thickness, pinhole aperture diameter and materials. Methods were identified and developed to quantifiably evaluate the image characteristics of spatial resolution and field of view. The collimation effect is observed most strongly for thick pure tungsten masks with narrow apertures. Small apertures give a much greater FOV sensitivity to changes in mask thickness, and similarly thick masks give a much greater sensitivity to the AOV. Thick pinhole masks have a very limited field of view (collimation effect) which results in images cropped at their edges. Images taken with coded apertures would exhibit partial coding and produce artefacts. For the best obtainable resolution, a $1 \mathrm{~mm}$ aperture must be used where only pure tungsten would suppress background noise enough to form an image with a $2 \mathrm{~mm}$ thick mask. The thickness of $\mathrm{W}$ Epoxy or $\mathrm{Bi}$ alloy required to match the background noise characteristics of $3 \mathrm{~mm}$ thick tungsten is $7 \mathrm{~mm}$, but this would give an unacceptable field of view. Pure tungsten appears the most versatile material tested and allows small pinholes to be used in thin masks.

\section{Acknowledgement}

The authors would like to thank Dstl for the financial support for this work.

Content includes material subject to @ Crown copyright (2018), Dstl, ref. number DSTL/JA107338. This material is licensed under the terms of the Open Government Licence except where otherwise stated. To view this licence, visit http://www.nationalarchives.gov.uk/doc/open-governmentlicence/version/ 3 or write to the Information Policy Team, The National Archives, Kew, London TW9 4DU, or email: psi@ nationalarchives.gsi.gov.uk.

\section{References}

[1] F. Salvat, "PENELOPE-2014: A code system for Monte Carlo simulation of electron and photon transport," OECD/NEA Data Bank, Issy-les-Moulineaux, France, 2015.

[2] E. E. Fenimore, "Coded aperture imaging: predicted performance of uniformly redundant arrays," Applied Optics, vol. 17, no. 22, p. 3563, 1978.

Published by Elsevier. This is the Author Accepted Manuscript issued with: Creative Commons Attribution Non-Commercial Licence (CC:BY:NC 4.0). The final published version (version of record) is available online at DOI: 10.1016/j.nima.2018.07.049. Please refer to any applicable publisher terms of use. 
Nuclear Instruments and Methods in Physics Research Section A: Accelerators, Spectrometers, Detectors and Associated Equipment Volume 905, 11 October 2018, Pages 119-128

https://doi.org/10.1016/j.nima.2018.07.049

[3] C. Fiorini, R. Accorsi and G. Lucignani, "Single Pinhole and Coded Aperture Collimation Systems for High-Resolution Gamma-Ray Imaging in Nuclear Medicine: a Comparative Study," IEEE Nuclear Science Symposium Conference Record, Vols. J0343, 2005.

[4] R. Accorsi, F. Gasparini and R. C. Lanza, "A Coded Aperture for High-Resolution Nuclear Medicine Planar Imaging With a Conventional Anger Camera: Experimental Results," IEEE Transactions on Nuclear Science, vol. 48, no. 6, 2001.

[5] R. Accorsi and S. D. Metzler, "Analytic Determination of the Resolution-Equivalent Effective Diameter of a Pinhole Collimator," IEEE Transactions on Medical Imaging, vol. 23, no. 6, 2004.

[6] M. Gieles, H. W. A. M. De Jong and F. J. Beekman, "Monte Carlo simulations of pinhole imaging accelerated by kernel-based forced detection," Phys. Med. Biol. , vol. 47, p. 1853-1867, 2002.

[7] R. J. Jaszczakt, J. Li, H. Wang, M. R. Zalutsky and R. E. Coleman, "Pinhole collimation for ultra-high-resolution, small- field-of-view SPECT," Phys. Med. Biol. , vol. 39, pp. 437, 1994.

[8] A. A. M. Muñoz, A. Vella, M. J. F. Healy, D. W. Lane, I. Jupp and D. Lockley, "3Dprinted coded apertures for x-ray backscatter radiography," in Proc. SPIE 10393, Radiation Detectors in Medicine, Industry, and National Security XVIII, 103930F, San Diego, California, 2017.

[9] J. Almansa, F. Salvat-Pujol, G. Díaz-Londoña, A. Carnicer, A. M. Lallena and F. Salvat, "PENGEOM - A general purpose geometry package for Monte Carlo simulation of radiation transport in complex material structures," Computer Physics Communications (in press), 2015.

[10] F. Salvat and J. M. Fernaddez-Varea, "Overview of physical interaction models for photon and electron transport used in Monte Carlo codes," vol. 46, pp. S122-S138, 2009.

[11] The MathWorks Inc., "MATLAB and Statistics Toolbox Release 2017a," Natick, 2017.

[12] S. D. Metzler and J. E. Bowsher, "Analytic Determination of Pinhole Collimator Sensitivity With Penetration," IEEE Transaction on Medical Imaging, vol. 20, no. 8, 2001.

[13] NIST, "XCOM: Photon Cross Sections Database," 17 December 2017. [Online]. Available: http://www.nist.gov/pml/data/xcom/index.cfm. [Accessed 01 April 2016].

[14] K. Rossmann, "Point spread-function, line spread-function, and modulation transfer function. Tools for the study of imaging systems," Radiology, pp. 257-272, 1969.

[15] D. R. Dance, S. Christofides, A. D. A. Maidment, I. D. McLean and K. H. Ng, Diagnostic Radiology Physics - A handbook for teachers and students, Vienna: IAEA International Agency Energy Agency, 2014. 